2. Slanar, O., et al., CYP2D6 polymorphism, tramadol pharmacokinetics and pupillary response Eur J Clin Pharmacol, 2006. 62(1): p. 75-6; author reply 77-8.

3. Slanar, O., et al., Miotic action of tramadol is determined by CYP2D6 genotype Physiol Res, 2007. 56(1): p. 129-36.

4. Kirchheiner, J., et al., Effects of the CYP2D6 gene duplication on the pharmacokinetics and pharmacodynamics of tramadol I Clin Psychopharmacol, 2008. 28(1): p. $78-83$.

5. Matouskova, O., et al., Pupillometry in healthy volunteers as a biomarker of tramadol efficacy J Clin Pharm Ther, 2011. 36(4): p. 513-7.

6. Connelly, M.A., et al., Pupillometry: a non-invasive technique for pain assessment in paediatric patients Arch Dis Child, 2014. 99(12): p. 1125-31.

Disclosure(s) Nothing to disclose

\section{P84 PEDIATRIC ONCOLOGY STUDIES TRIGGERED BY THE UNITED STATES (US) FOOD AND DRUG ADMINISTRATION (FDA) AND THE EUROPEAN UNION (EU) EUROPEAN MEDICINES AGENCY (EMA) AIM AT LABELS, NOT AT IMPROVED TREATMENT. SOME HARM YOUNG PATIENTS BY EXPOSING THEM TO SUBSTANDARD MONOTHERAPY INSTEAD OF COMBINATION TREATMENT}

K Rose*. Medical Science, Klausrose Consulting, Riehen, Switzerland

\subsection{6/archdischild-2019-esdppp.122}

Background Both FDA and EMA reward/demand pediatric oncology studies. Do they advance pediatric cancer care?

Methods We analysed publications of FDA representatives, ${ }^{1-3}$ FDA-triggered pediatric oncology studies in the literature and in www.clinicaltrials.gov, ${ }^{4}$ and FDA/EMA pediatric reports. ${ }^{5-6}$ Results FDA authors express two key assumptions: (1) children, defined as $<17 y$, need separate proof of efficacy; ${ }^{1-3}$ (2) with the exception of chronic myelogenous leukema, the biology of cancer in children is different from adult cancer. ${ }^{1}$ FDA-triggered studies investigated single cytoxics agents in heavily pretreated refractory/relapsed patients $\leq 21 \mathrm{y}^{2}{ }^{4}$ In these days, combination treatment with up to 13 cytotoxic agents was standard of care. ${ }^{7}$ Another round of treatment with a single chemotherapy agent did not increase survival, but rewarded companies with patent extension, researchers with publications, the FDA with labeled information. The EU expanded the definition of children to $<18 \mathrm{y}$ and demands 'pediatric investigation plans' (PIPs) also for rare diseases. One FDA-triggered package investigated ipilimumab in 'pediatric' melanoma; 13 EMA PIPs demand 'pediatric' studies in solid tumors including melanoma; two 'pediatric' monotherapy studies with ipilimumab and vemurafenib, respectively, were terminated in 2016, five others continue recruiting. ${ }^{3} 48$

Discussion FDA/EMA-requested/demanded 'paediatric' oncology studies focus on labels in administratively defined 'children'. FDA/EMA-used age limits are not physiological. FDA assumptions about different biology of 'pediatric' malignancies are

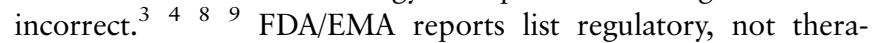
peutic achievements. ${ }^{5-6}$ Some EU researchers perform predominantly PIP-demanded oncology studies. In a cartel-like cooperation, the EMA demands such studies, threatening nonapproval of life-saving drugs. Researchers and EMA representatives co-author lauding reports. ${ }^{10}$

Conclusion FDA representatives augmented the flawed 'therapeutic orphans' concept by additional wrong assumptions about 'paediatric' malignancies' biology. ${ }^{1-4}$ The EMA further expanded the 'Paediatric Imperative'. Also PIPs do not advance treatment. Ethics committees should be alerted to re- analyze ongoing 'pediatric' studies, suspend questionable ones, and reject new ones. US+EU pediatric laws need revision.

\section{REFERENCES}

1. Snyder KM, et al. The impact of the written request process on drug development in childhood cancer Pediatr Blood Cancer. 2013;60:531-537.

2. Wharton GT, et al. Impact of pediatric exclusivity on drug labeling and demonstrations of efficacy Pediatrics. 2014;134(2):e512-e518.

3. Roberts $R$, et al. Pediatric Drug Labeling. Improving the Safety and Efficacy of Pediatric Therapies JAMA. 2003;290(7):905-911.

4. Rose K, Grant-Kels JM. Pediatric Melanoma - The Whole (Conflicts Of Interest) Story Int I Womens Dermatol 2018

5. FDA. Best Pharmaceuticals for Children Act and Pediatric Research Equity Act. July 2016. Status Report to Congress Department of Health and Human Services.

6. EMA. 10-year Report to the European Commission. General report on the experience acquired as a result of the application of the Paediatric Regulation.

7. Norris RE, Adamson PC. Challenges and opportunities in childhood cancer drug development Nat Rev Cancer. 2012 Nov;12(11):776-82.

8. Rose K, Walson PD. Are Regulatory Age Limits in Pediatric Melanoma Justified? Curr Ther Res Clin Exp. 2019

9. Pappo AS. Pediatric melanoma: the whole (genome) story. Am Soc Clin Oncol Educ Book. 2014:e432-5.

10. Ruperto $\mathrm{N}$ et al. A European Network of Paediatric Research at the European Medicines Agency (Enpr-EMA). Arch Dis Child. 2012 Mar;97(3):185-8.

Disclosure(s) The author has worked for more than 20 years in research \& development/medical affairs in pharma $\neg$ ceutical industry and is now an independent consultant, advising pharmaceutical companies and academic institutions in all aspects of pediatric drug development, organizing scientific conferences, publishing, \& more. The author's elder daughter is severely handicapped with a rare syndrom, which has biased him against empty governmental promises.

\section{P85 PREDICTION OF RALTEGRAVIR PLASMA CONCENTRATION IN HIV PAEDIATRIC PATIENTS USING PHYSIOLOGICALLY-BASED PHARMACOKINETIC MODEL}

F Salem* ${ }^{*}$ K Abduljalil, T Johnson. Certara UK Limited, Simcyp Division, Sheffield, UK

\subsection{6/archdischild-2019-esdppp.123}

Background Raltegravir is a drug used to treat patients with HIV infection. Understanding the disposition kinetics including the ontogeny of the major metabolic enzyme (UGT1A1) is important in prediction of raltaeravir pharmacokinetics in paediatric patients.

Methods Sim-Raltegravir compound file in Simcyp simulator version 18 was used to predict pharmacokinetics in paediatric subjects aged 4 weeks to 6 months, 0.5 to 2,2 to 6 and 6 to 12 years. Details of trial design were matched as closely as possible with a clinical study. ${ }^{1}$ Rate of absorption and variability in first order absorption model within Simcyp were set to the reported values. Predicted plasma concentration time profiles with 5 th and 95th percentile were compared with observations.

Results The predicted vs. observed geometric mean area under plasma concentration-time profile of raltegravir was 18.4 vs. $22.3 \mu \mathrm{M} . \mathrm{h}$ in subjects 4 weeks to 6 months and 16.5 vs. $19.8 \mu$ M.h in those 0.5 to 2 years old. In 2 to 6 and 6 to 12 year olds around $80 \%$ and $85 \%$ of observed data were within 5 th and 95 th percentile of the predictions.

Conclusion The results show that the UGT1A1 ontogeny profile in the Simcyp version 18 adequately addressed age-related differences in pharmacokinetics of raltegravir.

\section{REFERENCE}

1. Rizk, M., et al, J Clin Pharmacol 2015; 55(7):748-56 